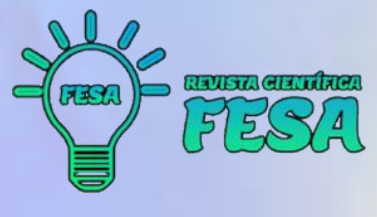

\title{
FORMAÇÃO CONTINUADA EM UM CONTEXTO DIGITAL
}

Giselle Pupim Jorge Back ${ }^{1}$

\begin{abstract}
RESUMO
A educação tem passado por constantes mudanças nos últimos tempos. Esse processo se intensificou com os novos formatos de aulas remotas em virtude do isolamento social em que os países estão passando. Os professores estão cada vez mais tendo de reorganizar planejamentos e modelos pedagógicos que contemplem essa nova organização. Nesse sentido, muito se tem discutido e refletido acerca do processo formativo contínuo dos docentes frente aos novos desafios da educação digital. Dessa forma o presente trabalho busca, através de uma pesquisa bibliográfica, proporcionar uma reflexão acerca da formação continuada e as tecnologias digitais. 0 aporte teórico estará balizado nos autores Nóvoa (2001), Schön (2000), Alarcão (2005) e Bacich e Moran (2018). Abordar aspectos sobre a formação continuada e as tecnologias digitais tornase relevante para o campo acadêmico educacional, pois permite analisar a percepção dos professores frente à formação continuada com uso das tecnologias digitais, uma vez que se torna imperiosa a percepção da visão desses profissionais de educação envolvidos nos processos formativos online, tendo em vista o espaço quase inexistente para os participantes emitirem sua opinião sobre esse formato de atualização docente. Sendo assim, é imprescindível ressaltar a importância da utilização de tais recursos no âmbito educacional uma vez que já faz parte do cotidiano social dos discentes e docentes. Através dos recursos tecnológicos conseguimos aprofundar nossos conhecimentos e, também, permite uma interação em tempo real.
\end{abstract}

Palavras-chave: Educação. Formação Continuada. Tecnologias Digitais.

\section{ABSTRACT}

Education has undergone constant changes in recent times. This process has intensified with the new formats of remote classes due to the social isolation that countries are experiencing. Teachers are increasingly having to reorganize pedagogical plans and models that contemplate this new organization. In this sense, much has been discussed and reflected on the teachers' ongoing training process in the face of the new challenges of digital education. Thus, the present work seeks, through a bibliographic search, to provide a reflection on continuing education and digital technologies. The theoretical contribution will be based on the authors Nóvoa (2001), Schön (2000), Alarcão (2005), Bacich e Moran (2018). Addressing aspects of continuing education and digital technologies becomes relevant to the academic academic field, as it allows analyzing the perception of teachers regarding continuing education with the use of digital technologies, since the perception of these professionals' views is imperative of education involved in the online training processes, in view of the almost non-existent space for participants to express their opinion on this format of teacher updating. Therefore, it is essential to emphasize the importance of using such resources in the educational scope, as it is already part of the social daily life of students and teachers. Through technological resources, we have been able to deepen our knowledge and, also, allow interaction in real time.

Keyword: Education. Continuing Education. Digital Technologies.

\section{RESUMEN}

La educación ha experimentado un cambio constante en los últimos tiempos. Este proceso se ha intensificado con los nuevos formatos de clases a distancia debido al aislamiento social en el

\footnotetext{
${ }^{1}$ Possui graduação em Pedagogia pela União das Faculdades de Alta Floresta (2004). Pós-graduação em Educação Interdisciplinar de $1^{\underline{a}}$ a $4^{\underline{a}}$ séries do Ensino Fundamental com ênfase em Educação Infantil e Alfabetização, da área do conhecimento Ciências Humanas. Mestrado em Ciências de Educação pelo Instituto IESA. Doutoranda em Ciências de Educação pelo Instituto IESA. Atualmente, é formadora do Centro de Formação e Atualização do Profissionais da Educação Básica/CEFAPRO-MT. E-mail: giselle.pupim@gmail.com
} 


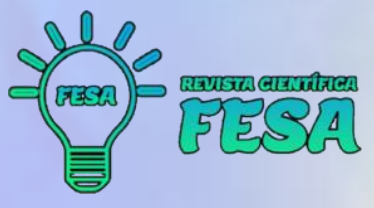

que atraviesan los países. Los docentes se ven cada vez más obligados a reorganizar los modelos de planificación y pedagógicos que contemplan esta nueva organización. En este sentido, mucho se ha debatido y reflexionado sobre el continuo proceso formativo del profesorado ante los nuevos retos de la educación digital. Así, el presente trabajo busca, a través de una investigación bibliográfica, proporcionar una reflexión sobre la educación continua y las tecnologías digitales. La contribución teórica será guiada por los autores Nóvoa (2001), Schön (2000), Alarcão (2005), Bacich e Moran (2018). Abordar aspectos de la educación continua y las tecnologías digitales cobra relevancia para el ámbito académico educativo, ya que permite analizar la percepción de los docentes frente a la educación continua con el uso de las tecnologías digitales, ya que se hace imperativo percibir la visión de estos profesionales de la educación involucrados en procesos de formación online, ante el espacio casi inexistente para que los participantes emitan su opinión sobre este formato de actualización docente. Por ello, es fundamental destacar la importancia de utilizar estos recursos en el ámbito educativo ya que ya forma parte de la vida cotidiana social de alumnos y profesores. A través de recursos tecnológicos podemos profundizar en nuestro conocimiento y también permite una interacción en tiempo real.

Palabras clave: Educación. Educación permanente. Tecnologías Digitales.

\section{INTRODUÇÃO}

Muito se tem dialogado acerca do uso das tecnologias digitais nas práticas pedagógicas dos professores bem como sua relação com o processo de ensino aprendizagem. Não podemos realizar tais altercações sem explorar a capacitação dos professores. É por meio dos momentos de estudos coletivos que os docentes podem analisar suas ações pedagógicas e refletir sobre as mesmas.

Quando se trata do desenvolvimento dos estudantes, alguns documentos precisam ser citados como forma de garantir que os alunos possam ter seus direitos de aprendizagens garantidos, como exemplo temos a "Declaração Mundial sobre Educação para Todos", que além do foco na no desenvolvimento cognitivo do aluno também estabelece relação direta com a formação docente.

Em uma sociedade com o desenvolvimento tecnológico acelerado como a nossa, somente transmitir conteúdo para os discentes não garante a aprendizagem ativa. É preciso prover estratégias metodológicas que chame a atenção dos estudantes, estimulando-os. Dentre os diversos recursos possíveis, as TICs além de chamar atenção de uma geração de nativos digitais permite uma interação em tempo real com toda a turma.

Vale ressaltar que os alunos conhecem e se apropriam com muita facilidade de toda essa gama digital, no entanto os docentes precisam se apropriar das ferramentas que muitas vezes estão sendo manuseadas pela primeira vez.

Dessa forma, os professores precisam estar em constante aprendizagem e isso gera desafios tanto para a aprendizagem quanto pelo caminho que se 
percorre até chegar nela. Para minimizar os desafios desse percurso, o professor precisa se tornar um eterno aprendiz para que possa ressignificar suas práticas com a integração das tecnologias digitais.

\section{FORMAÇÃO CONTINUADA}

A formação inicial consiste em uma graduação cursada por um estudante visando tornar-se um profissional da educação. Após esse processo inicial, os docentes passam por diversos momentos formativos durante sua trajetória profissional visando aperfeiçoar-se e apropriar-se das novas estratégias metodológicas para atender seus alunos. Esses momentos formativos que ocorrem na formação continuada proporcionam ao professor uma constante reflexão acerca de suas práticas pedagógicas relacionando-as com a teoria.

Nesta linha de pensamento - formação contínua - Nóvoa (1991) vê a possível saída para a melhoria da qualidade do ensino, dentro do contexto educacional contemporâneo. Sendo assim, as propostas para serem consolidadas precisam de novas posturas do docente frente ao saber, e a formação continuada auxilia nesse processo de grande importância. É nela que estão os desafios educativos e suas complexidades, a preocupação entre prática e teoria, entre reflexão e avaliação. Pode-se, nesses momentos, construir saberes através da coletividade, uma vez que não basta ser reflexivo individualmente. Precisa- se de colaboração total para se atingir o objetivo da melhoria da educação.

Nóvoa (2001) vê a formação como algo que pertence ao próprio sujeito e se inscreve num processo de ser (nossas vidas e experiências, nosso passado etc.) e num processo de ir sendo (nossos projetos, nossa ideia de futuro).

[...] apontam para a necessidade de se avançar e criar um novo paradigma, no qual a formação do educador se efetive num continuum, processo em que a formação inicial, a formação contínua, a prática profissional, os saberes da profissão e a carreira profissional sejam elementos articulados entre si (FUSARI, 1998, p.538-9; NÓVOA, 1992).

Para Nóvoa (2001), o aprender contínuo é essencial em nossa profissão. Se dedicar em duas vertentes: o professor e a escola. O educador enquanto agente transformador e a instituição como estabelecimento de crescimento profissional permanente. 
Para que o professor seja um transformador de sua realidade não basta ter um catálogo de cursos ou apenas teorias, é preciso momentos para refletir acerca de suas ações pedagógica.

Nessa direção, Schön (2000) aponta a formação de professores como um importante componente de ação acompanhado de reflexão que permite aos professores aprimorarem competências para atuarem em sala de aula. Também afirma que:

[...] podemos refletir no meio da ação, sem interrompê-la [...] e ainda se pode interferir na situação em desenvolvimento; nosso pensar serve para dar nova forma ao que estamos fazendo, enquanto ainda o fazemos. Eu diria, em caso como este, que refletimos-na-ação (SCHÖN, 2000, p. 32).

Na visão de Schön (2000), o professor precisa assumir o papel de orientador, tendo como principais atividades em um ensino prático: de mostrar, aconselhar, questionar e criticar. Para ele, quem ensina indiferente do local: na escola, laboratório, em campo ou em aulas de música, precisa reconhecer sua ignorância e desenhar seu projeto.

Essa reflexão, para Schön (2000), é um elo intimamente ligado a ação atuante, e permite somente através dela que há uma percepção da sua prática docente. Isso só é possível quando o professor consegue abstrair sua ação em sala de aula e refletir retrospectivamente visualizando todo o seu processo durante a ação pedagógica e como alguns desafios foram solucionados no decorrer.

Alarcão (2005) também acrescenta ainda que os professores têm de ser agentes ativos do seu próprio desenvolvimento e do funcionamento das escolas como organização ao serviço do grande projeto social que é a formação dos educandos.

E afirma que:

Uma prática reflexiva leva à (re) construção de saberes, atenua a separação entre teoria e prática e assenta na construção de uma circularidade em que a teoria ilumina a prática e a prática questiona a teoria" (ALARCÃO, 2005, p. 99).

Ainda ressalta a importância da atitude reflexiva do professor para a construção de alunos também reflexivos, utilizando com estratégias a metodologia, avaliação e reflexão sobre as ações realizadas, destacando que a reflexão 
sobre o trabalho docente precisa ser realizada no coletivo, e não por só um professor, essa ação isolada pode gerar aprendizagem limitada.

Quando o planejamento e reflexão ocorrem num ambiente colaborativo gera maior aprendizagem. Ao agir sozinho o decente influencia somente vinte ou trinta, ou seja, os alunos de sua turma, todavia quando essa prática atinge não só o professor mas o coletivo de professores de uma instituição essa se torna uma escola reflexiva, que é "aprendente e ensinante" (ALARCÃO, 2007).

\section{FORMAÇÃO CONTINUADA E TECNOLOGIAS DIGITAIS}

Ao dialogar acerca da formação continuada podemos observar a importância da reflexão acerca das teorias, bem como o trabalho colaborativo. Vale ressaltar que mediante ao cenário tecnológico atual as tecnologias digitais tornaram-se grandes aliados no percurso de ensino-aprendizagem tanto para 0 aluno quanto para o professor. Ao utilizar ferramentas como os aplicativos para ensinar um conteúdo o docente permite ao estudante uma maior interação com ferramentas que lhe são confortáveis.

Ao despertar no aluno a vontade de buscar e aprender permite desencadear a aprendizagem significativa através de uma metodologia ativa com uso das tecnologias. Importante mencionar que somente o protagonismo não é suficiente, o professor necessita apropriar-se das diversas estratégias para criar esses espaços de aprendizagem. Segundo Bacich e Moran (2018), muitas escolas mesmo com todos os recursos tecnológicos falham pois ensinam de forma burocrática, desestimulante, ultrapassada.

\footnotetext{
Sabe-se que temos problemas estruturais graves de formação, remuneração, infraestrutura, base comum, gestão; mas o problema essencial é humano: carência de gestores e docentes competentes que conversem entre si, ajudem-se, apoiem e façam o possível para motivar os alunos e ajudá-los a crescer e evoluir em todos os momentos (BACICH; MORAN, 2018, p.64).
}

Dessa forma, é fundante que as ações pedagógicas estejam engajadas com ferramentas que respondam aos anseios dos alunos. Posto isso é importante proporcionar altercações acerca das tecnologias digitais em sala de aula. E o momento para se refletir essas ferramentas pode ser a formação continuada, visto que seu papel é propiciar reflexões entre teoria e prática. 
Bacich e Moran (2018) destaca que "a junção de metodologias ativas com modelos flexíveis e híbridos traz contribuições importantes para o desenho de soluções atuais para os aprendizes de hoje." (BACICH; MORAN, 2018, p. 41). O autor destaca com muita ênfase o fato de unirmos momentos presenciais em sala de aula e momentos on line para introduzir ou aprofundar determinado conteúdo.

Assim, o uso das tecnologias digitais permite oferecer suportes aos seus alunos. Bacich e Moran (2018) complementa que as escolas que não possuem esses acessos no contexto atual são escolas incompletas, pois esses novos conceitos podem modificar o conceito de sala de aula e espaço.

Essas ferramentas permitem um estudo mais centrado no aluno, ou seja, mais personalizado. Sendo assim, o professor consegue analisar seu aluno, tanto isoladamente quanto coletivamente. Para Bacich e Moran (2018), esse olhar é primordial visto que:

[...] cada estudante, de forma mais direta ou indireta, procura respostas para suas inquietações mais profundas e pode relacioná-las com seu projeto de vida e sua visão de futuro, principalmente ao contar com mentores competentes e confiáveis (BACICH; MORAN, 2018).

Dessa forma essas estratégias visam potencializar as ações de ensino e aprendizagem por meio do envolvimento dos estudantes como autores do processo e não apenas como espectadores (BACICH; MORAN, 2018).

\section{DISCUSSÕES INTERNACIONAIS SOBRE A FORMAÇÃO CONTINUADA E TECNOLOGIAS DIGITAIS}

Muito se tem dialogado acerca da linha de pesquisa Formação Continuada e o uso das TICs, principalmente em um contexto contemporâneo. Essas discussões em foco são abordadas no contexto internacional desde a década de 90, com as diretrizes apresentadas pelo Banco Mundial na Tailândia através da "Declaração Mundial sobre Educação para Todos". Com o objetivo de fortalecer as necessidades básicas de aprendizagem para os estudantes, destaca que a utilização das tecnologias educativas pode melhorar a qualidade da educação.

A referida declaração destaca que "o uso da tecnologia moderna também permite melhorar a gestão da educação básica. Cada país deverá reavaliar 
periodicamente sua capacidade tecnológica presente e potencial, em relação aos seus recursos e necessidades básicas educacionais." (Artigo 26). Vale ressaltar que as necessidades básicas de aprendizagem dos estudantes estão diretamente relacionadas as práticas pedagógicas dos docentes, bem como sua formação quer seja inicial ou continuada.

A declaração, também, faz menção específica a formação dos docentes e sua relação com todo o processo final de resultados dos alunos e consequentemente a melhora da qualidade de ensino. Sendo assim, ressalva que

\begin{abstract}
A formação dos educadores deve estar em consonância aos resultados pretendidos, permitindo que eles se beneficiem simultaneamente dos programas de capacitação em serviço e outros incentivos relacionados à obtenção desses resultados; currículo e avaliações devem refletir uma variedade de critérios, enquanto que os materiais, inclusive a rede física e as instalações, devem seguir a mesma orientação. (ARTIGO 21)
\end{abstract}

Observa-se, assim, uma correlação entre a formação do professor, seu planejamento com uso de ferramentas tecnológicas enquanto pressuposto para a melhora da qualidade de ensino. Vale ressaltar que mesmo após trinta anos da Declaração Mundial sobre Educação para Todos, ainda nos deparamos com uma população minoritária com acesso e utilização constante de ferramentas tecnológicas.

Seguindo a correlação formação e ferramentas tecnológicas, em 2008, a Organização das Nações Unidas para a Educação, a Ciência e a Cultura (UNESCO), publica um documento intitulado: "Padrões de competência em TIC para professores" apresentando diretrizes para os professores incorporarem as TICs em suas práticas pedagógicas para o ensino primário e secundário.

\footnotetext{
Os programas de desenvolvimento profissional coordenados com essas políticas têm o objetivo de desenvolvera alfabetização tecnológica dos professores, de modo a integrar o uso das ferramentas básicas de TIC ao currículo escolar padrão, à pedagogia e às estruturas de sala de aula. Os professores devem saber como, onde e quando usar (ou não usar) a tecnologia para as atividades em sala de aula, para tarefas de gestão e para adquirir conhecimento adicional pedagógico e de conteúdo para, assim, apoiar o desenvolvimento profissional do próprio docente. (UNESCO, 2009)
}

O principal objetivo do projeto ao articular saber docente contínuo e alfabetização tecnológica para os alunos é proporcionar altercações acerca da 
capacitação dos docentes e o uso de novas tecnologias em sala de aula proporcionando um maior gerenciamento do ambiente de aprendizagem, por parte dos professores, partindo de ferramentas atuais para que os alunos possam compartilhar suas experiências e transcender os muros da escola.

Outro ponto importante a ser destacado, é o fato de o projeto estar articulado com a esfera real de seu avanço tecnológico, sendo assim cada país avalia seu contexto e sua realidade virtual e incorpora os módulos do projeto para que os docentes possam adquirir as competências necessárias.

É de suma importância a aquisição dessas competências uma vez que, conforme afirma Moran (2018):

O acesso fácil (infraestrutura, banda larga, mobilidade) e as competências digitais são fundamentais para implementar propostas educacionais atuais, motivadoras e inovadoras. Escolas deficientes em integrar o digital no currículo são escolas incompletas. (BACICH; MORAN, 2018, p. 11)

Partindo do acordado pela UNESCO, o Parlamento Europeu inclui a competência digital como sendo competência-chave para o desenvolvimento da aprendizagem, juntamente com o desenvolvimento da língua materna, da língua estrangeira e com ao aprender a aprender. Dessa forma, houve a necessidade de se criar um Quadro Europeu de Competência Digital (DigComp). O referido quadro apresenta 21 competências distribuídas em áreas que permite através de realização de determinadas tarefas enquadra-se em níveis nessas áreas. 0 maior desafio frente ao novo documento, não era o acesso a internet, pois a maioria da população o tinha. O grande desafio foi como atribuir níveis para considerar um indivíduo competente digitalmente ou não.

Sendo assim, a Comissão Europeia parte para a organização de destaque de componentes que permitam um indivíduo ser um competente digital, além de utilizar a aferição como ponto de partida para novas buscas e orientações. Em países como Espanha e Croácia os programas de formação profissional para os professores são balizados nas competências apresentadas no quadro seguindo sua complexidade a cada módulo. Vale ressaltar que a cada ano as competências e níveis são reorganizados para atender as demandas digitais dos países.

No Uruguai, encontramos políticas públicas voltada a atender a população através de investimentos para que a internet chegasse a $80 \%$ das casas 
possibilitando a comunicação e o trabalho a distância, inclusive as atividades escolares. Um dos projetos, Plano Ceibal, criado em 2007, recebe o nome da flor Ceibo, nacional do país. Nicholas Negroponte e outros membros do instituto de Tecnologia de Massachusetts implementam o programa que através da distribuição de computadores portáteis a crianças e adolescentes, nos anos de 2007 a 2018, permitiu a inclusão digital através do ensino público.

O plano dispões de plataformas virtuais que podem ser acessadas por alunos e professores que possibilitam realizar atividades, jogos, acesso a biblioteca e vídeo conferências. Também, permite aos professores tirarem dúvidas quanto ao processo de ensino remoto, uma vez que apresenta como meta específica articular o uso educativo de novos recursos com a formação e atualização dos professores.

Apresenta como objetivos:

1) Contribuir na melhoria da qualidade educativa mediante a integração da tecnologia em sala de aula, no centro escolar e no núcleo familiar;

2) Promover a igualdade de oportunidades para todos os alunos da Educação Primária, dotando de um computador portátil cada aluno e professor;

3) Desenvolver uma cultura colaborativa em quatro linhas: aluno-aluno, aluno-professor, professor-professor e aluno-família-escola;

4) Promover a alfabetização e criticidade eletrônica na comunidade pedagógica, atendendo aos princípios éticos (NAVARRETE, 2013).

Dessa forma, analisa-se através dos objetivos supracitados que além de pormenorizar os aspectos relacionados ao pedagógico, ao buscar uma melhoria na qualidade educacional, também envolve a família e a comunidade escolar.

O projeto inicialmente atenderia os alunos do Ensino Fundamental da rede pública com laptops com acesso à internet, porém se estendeu aos alunos da etapa do ensino Médio e as escolas privadas, em 2010.

Já o Ministério de Educação do Chile, busca atingir um maior número de estudantes com uso das tecnologias através do Plano Enlaces. Organizado desde 1992, atende professores e alunos visando implementar novas estratégias de ensino partindo do uso das tecnologias, além de fornecer capacitação aos docentes e workshops para os alunos. Também há uma preocupação com a estrutura digital das escolas para atender a demanda tecnológica dos estudantes e professores. 
Em 2018, o projeto terá mais quatro vertentes novas, possibilitando ao estudante possa aprender elementos básicos da programação de computadores, maior auxílio aos iniciantes nas competências digitais principalmente os discentes da modalidade Jovens e Adultos, maior autonomia e comunicação dos estudantes frente as tecnologias e maior conectividade para as instituições escolares.

Em uma das vertentes "Tecnologias de acesso universal para a educação", buscar-se-á dar maior suporte aos docentes e ao currículo educacional em si através de propostas metodológicas que permitam que os professores utilizem as TICs em seus planejamentos visando uma educação inclusiva.

A mesma discussão permeia o Ministério da Educação da Colômbia, integrando o desenvolvimento profissional como um dos principais focos para a melhora da qualidade educacional, destacando a importância do professor se aperfeiçoar e inovar-se pedagogicamente. Para o Ministério da Educação, a inovação educacional é vista como:

[..] a capacidade criativa que os professores podem desenvolver para reestruturar profundamente a tarefa pedagógica, mudando hábitos de ensino para propor novas soluções que respondam a as necessidades dos alunos e do ambiente escolar, dando lugar a novos estilos educacionais que possibilitem inclusão e equidade (ZÁRATE et al, 2017).

Um dos programas desenvolvidos pelo Ministério da Educação é o Antióquia Digital, inicialmente há o fornecimento de equipamentos digitais para as escolas, com aparelhos e internet. Vale ressaltar que os professores também recebem formação para que possam lidar com as diversas tecnologias bem como incorporá-las em seus planejamentos. Os professores formadores são separados por escolas, dessa forma cada tutor é responsável por auxiliar oito unidades escolares.

A interação dos alunos acontece de forma ativa, onde os mesmos podem participar de games envolvendo vários alunos de várias escolas diferentes, visando auxiliar no processo de ensino aprendizagem através da interatividade.

Já na Austrália, as políticas públicas educacionais estão envolvendo os alunos e docentes muito além de somente utilizar os recursos digitais, estão vislumbrando que os discentes possam raciocinar e criar soluções para os 
diversos problemas fazendo uso dos recursos digitais para melhorar o desenvolvimento do ser humano em uma sociedade.

Por meio do desenvolvimento de competências que permitem ao aluno criticar, analisar e avaliar problemas, necessidades ou oportunidades para identificar e criar soluções, apresentam um dos documentos mais rigorosos quanto ao uso das TICs, com orientações para alunos, professores e pais abordando desde conteúdos até as avaliações. Sendo assim, as tecnologias digitais permeiam todas as disciplinas dos currículos dos estudantes.

Pra que as competências digitais possam ser desenvolvidas nos alunos os professores têm acesso a materiais que permitem todo o processo de desenvolvimento do currículo das unidades escolares, desde as metas a serem atingidas em cada fase até um detalhamento minucioso de cada disciplina do currículo e suas diversas potencialidades.

Essa nova organização curricular australiana foi implantada em 2015, sendo assim o prazo para avaliar os resultados ainda são curtos. Vale ressaltar que mesmo frente ao prazo curto para avaliação mais precisa, a Austrália já ocupa o terceiro lugar, dos quatorze países que realizaram a prova International Computer and Information Literacy Study. (ICILS)

Já no Chile o uso das TICs é implantado nas unidades escolares através do Programa Enlaces, com o objetivo de tornar obrigatório das tecnologias no currículo escolar chileno. As TICs permeiam todas as disciplinas além de serem específicas sendo considerado como primordial para o desenvolvimento da aprendizagem.

São disponibilizados materiais que enriquecem as práticas dos professores bem como as ações dos alunos, através de plataformas gratuitas. O intuito é possibilitar no aluno o desenvolvimento e aprendizagem das principais ferramentas digitais como o uso de programas simples como o desenho, passando pela rede de comunicações até fazer uso das tecnologias como ferramenta de pesquisa atendendo as necessidades coletivas.

No campo da formação docente possuem orientações acera da organização curricular e sua relação com o planejamento. O programa supracitado oferece capacitação aos professores orientando os planejamentos a fim de atingir os objetivos e metas propostos.

\section{CONGRGÂNAASTEÓRCASDOMNDOCONIEMPORÂNEO}




\section{POLÍTICA NACIONAL DA FORMAÇÃO CONTINUADA E TECNOLOGIAS DI- GITAIS}

A profissão docente está frente a uma nova organização de tempo e espaço tomado pela realidade digital deste século. Sendo assim, somente a transmissão de conhecimento não é suficiente diante desse contexto.

As transformações que ocorreram nas últimas décadas têm afetado consideravelmente todo o processo de formação docente, quer seja inicial ou contínua. Encontramos um divisor de águas que permite um ressignificar da educação: o uso das tecnologias digitais. A cada dia a escola e mesma a educação tenta se reinventar, porém há a necessidade de parceiras com políticas públicas para que haja êxito no processo de acesso e democratização das tecnologias digitais nas escolas.

Ao dialogar acerca das políticas públicas educacionais e o uso das TICs, remetemos nosso foco para a Lei de Diretrizes e Bases da Educação ㄲo 9.394 de 1996, que influenciam diretamente tanto na formação inicial quanto continuada, partindo da articulação entre estados e municípios visando garantir a capacitação dos profissionais da educação. Ao articular a LDB/96 com a Lei 12.056/2009, a formação ganha uma maior abrangência através dos recursos tecnológicos frente a educação à distância.

Sendo assim, para incorporar as TICs na educação alguns programas desenvolvidos com auxílio do Ministério da Educação que permite levar a tecnologia digital para professores e alunos das diversas redes de ensino.

O Programa Nacional de Formação Continuada em Tecnologia Educacional (Prolnfo Integrado), consiste em desenvolver formação para os docentes acerca do uso das TICs, de forma didática e pedagógica, além de distribuir equipamentos nas escolas. Através de inscrições os docentes podem participar de cursos voltados aos principais recursos das TICs, como também preparar o professor para que compreendam seu papel frente a cultura digital.

O curso é desenvolvido em módulos para os professores e gestores escolares cuja unidade escolar a prior tenha sido contemplada com alguns computadores recebidos pelo MEC com a especificidade do programa Linux. As 
escolas receberam inicialmente dez computadores com o Linux Educacional, data show e internet que permitisse a realização das tarefas.

Outro projeto desenvolvido no âmbito nacional em parceria com a Presidência da República, elegeu cinco escolas pilotos para proporcionar a cada aluno um universo de aprendizagem digital através de um dispositivo com acesso à internet que permite o trabalho interativo e utilização de ferramentas digitais. O Projeto UCA - Um Computador por Aluno tornou-se complemento dos programas do MEC, especificamente do Proinfo, que visa atender os alunos do Ensino Fundamental e Médio.

Visando proporcionar a inclusão digital para os docentes através das políticas públicas, as Diretrizes Curriculares Nacionais para a Formação de Professores da Educação Básica vislumbram a interação das TICs com o processo pedagógico, a fim de permitir o aperfeiçoamento das ações pedagógicas dos docentes. As discussões permeiam sempre a forma como as formações e capacitações são desenvolvidas pelos docentes além de relacioná-las com sua efetivação.

As Diretrizes são definidas partindo da Resolução № 2, de 20 de dezembro de 2019, que dispõe acerca da implantação da Base Nacional Comum Curricular e da BNC- Formação. A referida Resolução discorre acerca da organização da formação inicial e continuada dos docentes, destacando como habilidade, na dimensão da prática profissional, a utilização das tecnologias digitais para potencializar as aprendizagens dos estudantes.

A BNCC, um documento de caráter normativo permite as instituições escolares, organizar seus próprios currículos baseados em habilidades consideradas essenciais para o desenvolvimento da aprendizagem. No documento, os direitos de aprendizagens são garantidos aos alunos desde a Educação Infantil até o Ensino Médio, sempre fazendo menção as tecnologias perpassando o letramento digital e científico.

Ainda no âmbito educacional brasileiro temos o Programa de Inovação Educação Conectada, que através do Ministério da Educação m colaboração com o Ministério da Ciência, Tecnologia, Inovações e Comunicações, Banco Nacional de Desenvolvimento Social, o Centro de Inovação para a Educação Brasileira, o Conselho Nacional de Secretários da Educação e União Nacional dos 
Dirigentes Municipais de Educação, buscar possibilitar um acesso universalizado da internet bem como estimular o uso das TICs no contexto educacional.

A adesão ao programa acontece através do Sistema Integrado de Monitoramento Execução e Controle (Simec). Em seguida realiza-se um diagnóstico através do próprio sistema para que possam ser deliberadas as ações a serem desenvolvidas nas unidades escolares. As ações são balizadas nas quatro dimensões do programa: estimula a planejar partindo das inovações tecnológicas; formação para os professores implementarem o programa; recursos a serem utilizados em sala de aula; acesso à internet e infraestrutura.

O foco principal do programa é garantir que a instituição escolar esteja preparada para as novas tecnologias, desde a formação dos professores, a infraestrutura e a familiarização dos alunos frente as TICs.

Os estados brasileiros contam com secretarias específicas para políticas públicas educacionais que trabalham me parceiras com o Ministério da Educação. No estado de Mato Grosso, a Secretaria de Estado e Educação - SEDUC :

[...] tem a finalidade de propor e executar políticas públicas voltadas à Educação Básica assegurando ao estudante o desenvolvimento de capacidades e a construção de conhecimentos para a formação de valores humanos na conquista da cidadania, conforme define seu Regimento Interno, aprovado pelo Decreto №328, de 16.12.19. (SEDUCMT, Plano Estratégico Volta às Aulas, pág. 09)

A SEDUC/MT, também visa articular através de tempo de capacitação profissional em serviço o desenvolvimento dos direitos de aprendizagem dos estudantes. Sendo assim, os docentes precisam destinar um terço de seu tempo de planejamento pedagógico para capacitar-se profissionalmente.

Outra preocupação constante dessa secretaria é a articulação da aprendizagem do aluno, desenvolvimento profissional e as tecnologias digitais. No atual contexto de pandemia, a influência das tecnologias digitais tornou-se ainda mais presente, uma vez que a primeira deliberação foi a suspensão das aulas presenciais.

Para que pudesse ser realizada a retomada das atividades escolares de forma remota, o governo de Mato Grosso, especificamente a SEDUC-MT, organiza um plano estratégico visando atender os 367.450 estudantes da rede estadual de ensino mato-grossense. Vale ressaltar que a elaboração do plano tem 
uma configuração global apresentando as principais diretrizes educacionais para retomada das atividades de forma não presencial, porém cada escola elaborou seu plano estratégico balizada em sua realidade institucional garantindo a conclusão das 800 horas letivas no currículo de 2020.

Inicialmente para atender os alunos foram elaboradas e disponibilizadas atividades para os alunos realizarem através de uma plataforma "Aprendizagem Conectada". Os materiais elaborados pela Superintendência de Formação em parceria com os Centro de Formação e Atualização dos Profissionais da Educação eram disponibilizados semanalmente. Importante mencionar que as atividades permitiam uma resolução tanto on line como off line. As atividades elaboradas a partir de setembro serão de responsabilidades do professor e o atendimento dos alunos acontece desde o dia 03 de agosto através de uma plataforma da Microsoft Teams.

Os professores recebem capacitação profissional para o uso do recurso tecnológico bem como a elaboração do material a ser confeccionado para os alunos, bem como acerca das ferramentas da plataforma utilizada pelo estado.

\section{CONSIDERAÇÕES FINAIS}

O modelo educacional ao qual estamos habituados consiste em transmissões de conhecimento no qual o professor expõe o conteúdo e o aluno perpassa de forma passiva todos eles. Esse modelo permite, de forma muito restrita, o diálogo e interação, tornando aluno dependente do professor. Para que seja possível mudar esse protótipo educacional e os alunos possam desenvolver suas competências, é fundamental uma nova perspectiva acerca das práticas docentes e os recursos utilizados em sala de aula. As tecnologias digitais podem ser colaboradores importantes nesse processo. O uso de ferramentas virtuais contribui para uma nova roupagem as ações dos professores.

Vale destacar que somente o uso de recursos tecnológicos não permite uma ressignificação da educação e não proporciona sozinha uma aprendizagem significativa. É preciso ir mais além, refletindo acerca de todo o processo de ensino aprendizagem. Ao dialogar com relação entre teoria e prática pedagógica, remete-se os olhares para os momentos de estudos formativos que as escolas proporcionam aos professores. É no momento da formação continuada que os 


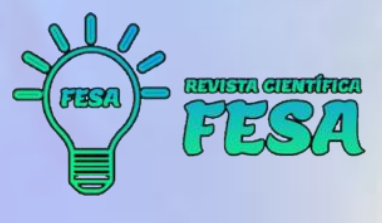

professores, podem além de apropriarem do recurso tecnológico em si pode refletir sobre seu uso e sua importância no contexto educacional.

É a partir dessas discussões que os docentes podem perceber ou mesmo aprofundar tais percepções acerca das tecnologias digitais enquanto direcionadoras de um desenvolvimento pedagógico mais ativo para seus estudantes permitindo uma ampliação não somente no desenvolvimento intelectual, mas também cultural. Além de contribuir para uma nova concepção de currículo escolar balizado em ações ativas e aprendizagens significativas, através de um direcionamento não somente temporal, mas espacial também.

\section{REFERÊNCIAS BIBLIOGRÁFICAS}

ALARCÃO, Isabel (Coord.). Formação reflexiva de professores: estratégias de supervisão. Porto: Porto Editora, 2005.

BACICH, Lilian; MORAN, José. Metodologias ativas para uma educação inovadora: uma abordagem teórico-prática [recurso eletrônico] - Porto Alegre: Penso, 2018 e-PUB.

BASSO, Ilda. Formação continuada de professores = competencias e uso da linguagem digital. 2009. 241 p. Tese (doutorado) - Universidade Estadual de Campinas, Faculdade de Educação, Campinas, SP. Disponível em: <http://www.repositorio.unicamp.br/handle/REPOSIP/251658>. Acesso em: 10 ago. 2020.

NASCIMENTO, Silma Pereira do. As TIC na formação continuada de professores: desafios para os núcleos de tecnologia educacional no Estado de Goiás. Anápolis: Centro Universitário de Anápolis -UniEvangélica, 2015. Disponível em: <http://www.unievangelica.edu.br/files/images/Silma\%20pereira.pdf> Acesso em: 10 ago. 2020.

NÓVOA, Antônio (1992 a). Formação de professores e profissão docente. In: NÓVOA (org.). Os professores e a sua formação. Lisboa: Publicações Dom Quixote.

PORVIR. Departamento colombiano investe em TICs para revolucionar a educação. Disponível em: < https://porvir.org/departamento-colombiano-investe-emtics-para-revolucionar-educacao/> Acesso em 17 de ago. 2020

PORVIR. Aluno aprende sozinho a usar tecnologia, mas o professor garante segurança na internet. Disponível em: https://porvir.org/aluno-aprende-sozinho-ausar-tecnologia-mas-e-o-professor-quem-garante-seguranca-na-internet/ > Acesso em 20 de ago. 2020. 
SCHÖN, Donald. Educando o Profissional Reflexivo: um novo design para o ensino e a aprendizagem. Trad. Roberto Cataldo Costa. Porto Alegre: Artmed, 2000, 256p.

SILVA, Denis Antônio. A formação continuada em tecnologias digitais ofertada no Paraná sob a ótica de professores da rede estadual de Foz do Iguaçu. 2018. 137 f. Dissertação (Mestrado em Ensino) - Universidade Estadual do Oeste do Paraná, Foz do Iguaçu, 2018. Disponível em: < http://tede.unioeste.br/handle/tede/3647>. Acesso em: 24 ago. 2021.

NAVARRETE, Helena Maria Cecilia. O Plano CEIBAL e a constituição de ambientes comunicacionais em escolas, praças e famílias. Dissertação (mestrado). Faculdade Cásper Líbero, Programa de Mestrado em Comunicação - São Paulo, 2013.

UNICEF. Declaração Mundial sobre educação para Todos. Disponível em: https://www.unicef.org/brazil/declaracao-mundial-sobre-educacao-para-todosconferencia-de-jomtien-1990 Acesso em 12 de ago.2020.

ZÁRATE, Laitón; VIVIANA, Erika; ARDILA, Gómez; EDUARDO, Sergio; PORRAS, Sarmiento; EDUARDO, Román; CAROLINA, Mejía Corredor. Competencia de prácticas inclusivas: las TIC y la educación inclusiva en el desarrolloprofesional docente. Sophia, vol. 13, núm. 2, 2017, pp. 82-95 Universidad La Gran Colombia Quindío, Colombia Disponível em: < https://www.redalyc.org/jatsRepo/4137/413751844009/index.html> Acesso em 15 de ago. 2020 